\title{
RESEÑAS
}




\section{MAX WEBER Y LA UNIVERSIDAD}

\section{Libardo González}

El último número de la Revista Colombiana de Educación, la publicación periódica de la Universidad Pedagógica Nacional, publica por primera vez en español los textos sueltos de Max Weber sobre la universidad alemana: El poder del Estado y la dignidad de la vocación académica. Este volumen es el resultado de un conjunto de trabajos polémicos escritos por Max Weber en diversos períodos de su vida. Provienen de conferencias, ensayos, ponencias, artículos periodísticos y respuestas y notas aclaratorias difundidas por la prensa alemana de la época. Los primeros fueron escritos en 1908 y los últimos en 1917 y en 1918. En conjunto estudian las relaciones universidad-Estado, los fundamentos de la libertad académica, la responsabilidad de los profesores universitarios y las normas que rigen la conducta de los hombres de ciencia. Buena parte de ellos están escritos en un tono de indignación moral y de vindicación ética de la autonomía de la ciencia ante la intromisión de los intereses políticos y religiosos. Su objetivo central es la afirmación de la ciencia como una ocupación vocacionalmente orientada, esto es, como la entrega total a un oficio donde sólo cuentan la honestidad personal y la providad intelectual.

Max Weber, la cumbre de la sociología alemana de comienzos de siglo, no fue ajeno a las controversias "menudas" de su época. En varias ocasiones abandonó el gabinete del estudioso para debatir asuntos en apariencia baladíes. Lo que a su juicio era una arbitrariedad de las autoridades educativas, de sus colegas o del sistema imperante, lo combatía con rigor y pasión, dos virtudes escasas en la universidad de nuestros días.

Su ejemplo, su lucha por la depuración de la ciencia y del trabajo académico, ha llevado a la Universidad Pedagógica Nacional a rescatar esta faceta poco conocida de la personalidad de Max Weber. En El poder del Estado y la dignidad de la vocación académica surge un Weber airoso en contra de los exabruptos cometidos por funcionarios que nombran profesores sin atender los requisitos intelectuales, la calidad ética del docente o el concepto de la comunidad académica. Esto ocurría en la Prusia de 1908. Weber analiza el caso del profesor Ludwig Bernhard, nombrado por el director de asuntos universitarios del Ministerio de Educación en la Universidad de Berlín sin consultar las autoridades universitarias. Según la tradición, que Weber califica de sana, el Ministerio se saltó el procedimiento que debía partir de la terna presentada por los miembros de la Facultad. Weber escribió una airada protesta no sólo contra el funcionario, sino contra el mismo profesor Bernhard por faltar a la ética del docente.

El caso Bernhard llevó a Weber a cuestionar otras prácticas corrientes en la Alemania de la época. En aquellos años se obstaculizaba el nombramiento en la universidad de prominentes intelectuales por el sólo hecho de ser socialistas, marxistas o judíos. Este fue el caso de Georg Simmel, Robert Michels y Werner Sombart. Los dos primeros eran "hebreos" y el último un social-demócrata muy cercano a las doctrinas de Karl Marx. Weber arremetió contra estas prácticas, afirmando una y otra vez que en la esfera de la ciencia poco contaban la raza, la política y la religión. Allí el talento y la entrega total al oficio - la vocación- eran los únicos rasgos objeto de aplauso. El profesor debía ceñirse a su especialidad y ofrecer a sus estudiantes el producto de sus estudios y desvelos científicos fuera de toda pasión partidaria.

La mirada de Weber también se volcó sobre el clima de las instituciones. Encontró entidades caducas como las Escuelas de Comercio que alimentaban valores vinculados 
con la tradición medieval. Allí el "honor" de claro sabor castrense, los duelos y encuentros de espadachines, ocupaban un lugar importante en la formación de sus estudiantes. Al comparar esta situación con la de los Estados Unidos, país que visitó y observó atentamente, encontró que una parte significativa de la universidad alemana estaba muy lejos de las demandas del momento. Los nuevos tiempos exigían hombres capaces de enfrentar las complejidades del mundo industrial - comerciantes y financistas - y no valientes con cicatrices y caras laceradas ostentando una "honra" asociada con el desueto feudalismo alemán.

La cuidadosa versión española a cargo de Yolanda Ramírez-Prado del Departamento Nacional de Planeación y de Gonzalo Cataño de la Universidad Pedagógica Nacional, constituye un acontecimiento intelectual en nuestro medio. Su traducción viene acompañada además de amplias notas explicativas que facilitan la lectura y comprensión de los textos por parte de los lectores hispanoamericanos. Gracias a su trabajo podemos tener acceso a una de las mentes más privilegiadas de la cultura alemana y a una de las "furias" académicas más aceradas que pueda mostrar el mundo intelectual.

Nunca se hizo tan pertinente la traducción y compilación de estos trabajos para la reflexión y análisis de la universidad colombiana, sumida en una crisis que no parece tener límites. La injerencia de la política en el nombramiento de rectores y profesores; el uso de la educación como tráfico y enriquecimiento personales; la erosión de los principios éticos entre sus estudiantes, profesores y directivas; y especialmente, el abandono de todo control y exigencia por la calidad y relevancia de los contenidos. Por fortuna los alemanes contaban con la conciencia y la despiadada crítica de un Max Weber. Pero si en Colombia carecemos de una figura de su temple, el ejemplo del legendario profesor de Heidelberg debería servir para rescatar los grandes objetivos de la universidad: ser la depositaria de la ciencia, la difusora de la ética de la responsabilidad intelectual y la multiplicadora de los valores más preciados de la cultura occidental. 